\title{
Kahweol decreases hepatic fibrosis by inhibiting the expression of connective tissue growth factor via the transforming growth factor-beta signaling pathway
}

\author{
Hye-Young Seo ${ }^{1,2}$, Yun-A Jung ${ }^{1,2}$, So-Hee Lee ${ }^{1,2}$, Jae Seok Hwang ${ }^{1}$, Keun-Gyu Park ${ }^{3}$, \\ Mi-Kyung Kim ${ }^{1,2}$ and Byoung Kuk Jang ${ }^{1,2}$ \\ ${ }^{1}$ Department of Internal Medicine, Keimyung University School of Medicine, Daegu, South Korea \\ ${ }^{2}$ Institute for Medical Science, Keimyung University School of Medicine, Daegu, South Korea \\ ${ }^{3}$ Department of Internal Medicine, Kyungpook National University School of Medicine, Daegu, South Korea \\ Correspondence to: Byoung Kuk Jang, email: jangha106@dsmc.or.kr \\ Keywords: kahweol, hepatic fibrosis, CTGF, TGF- $\beta$ \\ Received: January 17, $2017 \quad$ Accepted: July 06, $2017 \quad$ Published: August 01, 2017 \\ Copyright: Seo et al. This is an open-access article distributed under the terms of the Creative Commons Attribution License 3.0 \\ (CC BY 3.0), which permits unrestricted use, distribution, and reproduction in any medium, provided the original author and source \\ are credited.
}

\section{ABSTRACT}

Kahweol is a diterpene molecule found in Coffea Arabica beans. Previous studies have shown that coffee reduces liver fibrosis, but it is not clear which component of coffee has the protective effect. In this study, we examined whether kahweol has a protective effect on hepatic fibrosis in vivo and in vitro. Kahweol decreased hepatic fibrosis by inhibiting connective tissue growth factor (CTGF) expression in thioacetamide (TAA)-treated mice. The expression of phospho-Smad3, signal transducer and activator of transcription 3 (STAT3), extracellular signal-regulated kinases (ERK), and c-Jun $\mathrm{N}$-terminal protein kinase (JNK) increased in the livers of TAA-treated mice and decreased in the kahweol-treated group. Kahweol significantly decreased the expression of transforming growth factor beta (TGF- $\beta$ )-stimulated type I collagen and CTGF expression in vitro. In addition, kahweol significantly decreased the expression of Smad3, STAT3, ERK and JNK, which are involved in the induction of CTGF expression by TGF- $\beta$ in hepatocytes, but not in HSCs. These results suggest that kahweol may be a new candidate for treatment of liver fibrosis.

\section{INTRODUCTION}

Coffee is the most widely consumed, pharmacologically active beverage in the world. It is a complex mixture of more than 1000 compounds such as caffeine, chlorogenic acid, melanoidins, and diterpenes $[1-3]$. The various antioxidants in coffee have protective effect against tumors, diabetes, and Parkinson's disease $[1,4,5]$. Kahweol, a diterpene molecule, is one of the constituents of coffee from the beans of Coffea arabica. This compound is present in unfiltered coffee drinks such as espresso, boiled coffee, or Greek coffee [6]. It is also well known that kahweol is anti-inflammatory and antiangiogenic, and is therefore anti-cancerous $[7,8]$.

Hepatic fibrosis is characterized by excessive and abnormal deposition of extracellular matrix (ECM) proteins. Hepatic stellate cells (HSCs) are activated during the progression of liver fibrosis and are a major source of ECM proteins in the liver. Following injury to the liver, quiescent HSCs are transformed into myofibroblast like cells, which are characterized by the expression of alpha smooth muscle actin ( $\alpha$-SMA) and deposition of collagens [9-11].

Connective tissue growth factor (CTGF/CCN2) is a secreted matricellular protein with very complex biology. It participates in the regulation of biological processes, including cell adhesion, migration, proliferation and angiogenesis, and extracellular matrix production [12]. CTGF is expressed in response to tissue injury and is used as a biomarker of hepatic fibrosis [13]. Earlier studies reported that transforming growth factor beta (TGF- $\beta$ ) induced CTGF expression in hepatocytes and this CTGF 
is associated with the development of hepatic fibrosis $[14,15]$. TGF- $\beta$ signaling and its signaling pathway members, Smads, are regarded as the key fibrogenic signals contributing to liver fibrosis. Signal transducer and activator of transcription 3 (STAT3) is involved in activating CTGF. STAT3 activation accompanies enhanced phospho-Smad3 and CTGF expression in liver fibrosis.

Previous studies have shown that coffee decreases hepatic fibrosis by decreasing the expression of CTGF $[16,17]$. Although there is some evidence that coffee has protective effect against hepatic fibrosis, it is not clear which constituents of coffee have this protective effect. In this study, we investigated whether kahweol has a protective effect against hepatic fibrosis in in vitro and in vivo models.

\section{RESULTS}

\section{Kahweol decreased TAA-induced hepatic fibrosis}

To determine whether kahweol has protective effects against hepatic fibrosis, we first examined the change in hepatic pathology in a thioacetamide (TAA)-induced hepatic fibrosis mouse model. Hematoxylin and eosin (H\&E) and Sirius red staining revealed markedly elevated fibrosis following TAA treatment. However, TAA-induced hepatic fibrosis was significantly decreased by kahweol treatment (Figure 1A). Furthermore, immunohistochemical (IHC) staining showed that the kahweol-treated group had significantly reduced hepatic expression levels of type I collagen and $\alpha$-SMA (Figure 1B). Real-time PCR and western blot analysis also revealed that the expression of TGF- $\beta$, collagen and $\alpha$-SMA were increased in the TAA-treated group, and this effect was inhibited by kahweol treatment (Figure 2A and 2B). We also examined the changes in serum alanine transaminase (ALT) and aspartate transaminase (AST) levels. The levels of ALT and AST were significantly higher in the TAA-treated group than in the normal control group. The kahweoltreated group displayed significantly lower levels of serum ALT and AST (Figure 2C). Taken together, these findings suggest that kahweol has protective effects against TAAinduced hepatic fibrosis.

\section{Kahweol decreased CTGF expression}

CTGF is a strongly profibrogenic molecule that is overexpressed in fibrotic liver disease and mainly upregulated by TGF- $\beta$. The protein and mRNA expression of CTGF and TGF- $\beta$ were upregulated in the livers of
A

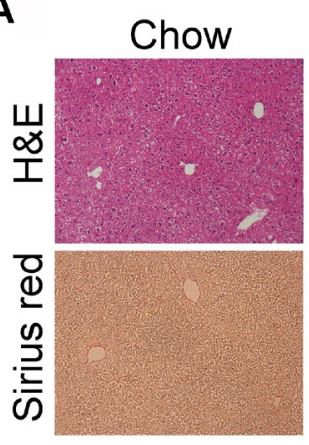

B

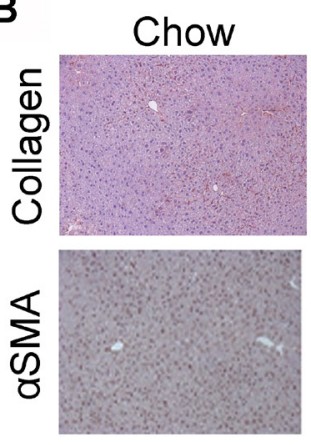

TAA
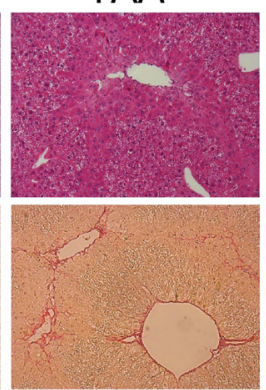

TAA

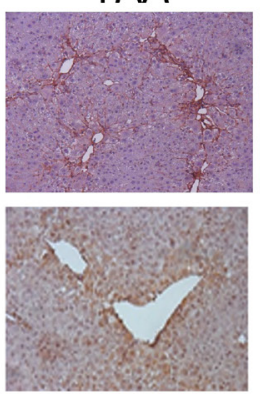

TAA+Kah

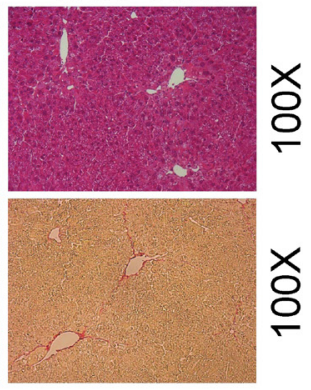

TAA+kah

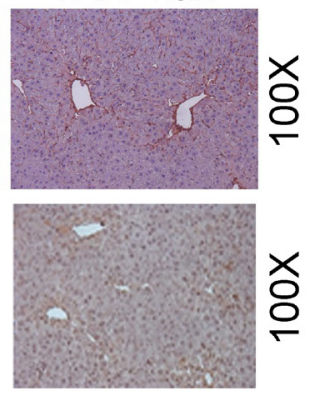

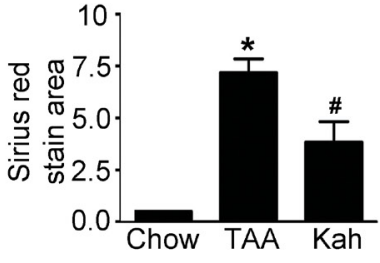
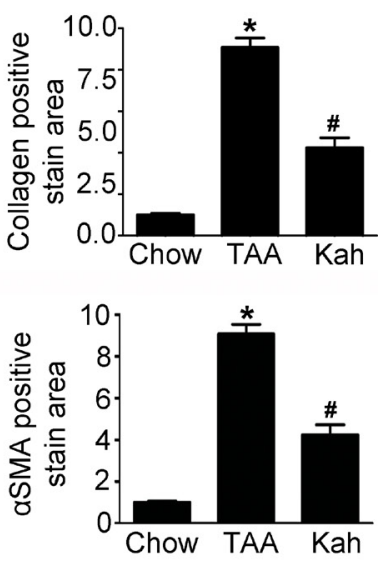

Figure 1: Kahweol decreases TAA-induced hepatic fibrosis in mice. (A) Representative images of hematoxylin and eosin (H\&E) staining and sirius red staining of liver tissue sections from mice after TAA-injection. Areas of positive staining with Sirius red were quantitated by computer-based morphometric analysis. Data are means $\pm \mathrm{SEM}$ of five random fields from each liver. Magnification: $100 \mathrm{X}$. ${ }^{*} P<0.05$ compared with chow group, ${ }^{\#} P<0.05$ compared with TAA-injection group. (B) Representative images of immunohistochemical staining of liver tissue sections from mice after TAA-injection. Areas of positive staining with antibodies against type I collagen and $\alpha$-SMA were quantitated by computer-based morphometric analysis. Data are means \pm SEM of five random fields from each liver. Magnification: 100X. ${ }^{*} P<0.05$ compared with chow group, ${ }^{\#} P<0.05$ compared with TAA-injection group. 
the TAA-treated group (Figure 3A). However, kahweol decreased the TAA-induced CTGF and TGF- $\beta$ expression. Consistent with the results of the in vivo study, kahweol significantly reduced TGF- $\beta$-stimulated type I collagen expression in LX2 cells. Kahweol also decreased TGF$\beta$-stimulated CTGF expression in AML12 cells, primary hepatocytes, and LX2 cells (Figure $3 \mathrm{~B}$ and $3 \mathrm{C}$ and Supplementary Figure 1).

\section{Kahweol inhibited phospho-Smad3 expression}

The TGF- $\beta /$ Smad pathway is one of the most important pathways among the multiple signaling pathways that affect CTGF expression [18]. Therefore, we investigated whether kahweol inhibits phosphoSmad3 expression. Expression of phospho-Smad3 and its subsequent nuclear translocation are critical steps in the signaling cascade that results in hepatic fibrosis. As expected, in the TAA-treated group, Smad2 and Smad3 accumulated in the nucleus (Figure 4A). However, the nuclear translocation of $\mathrm{Smad} / 3$ was impaired in the kahweol-treated group. Consistent with the in vivo findings, kahweol also inhibited TGF- $\beta$-stimulated phospho-Smad3 protein expression in both AML12 cells and primary hepatocytes (Figure 4B). Kahweol decreased type I collagen expression, but did not decrease TGF$\beta$-stimulated phospho-Smad3 expression in LX2 cells (Figure 4C).

\section{Kahweol inhibited phospho-STAT3 expression}

Next, we investigated whether the inhibitory effects of kahweol on hepatic fibrosis were mediated via STAT3, because hepatic fibrosis is associated with STAT3 phosphorylation [19]. TAA treatment increased phosphoSTAT3 expression in the livers of the TAA-treated group
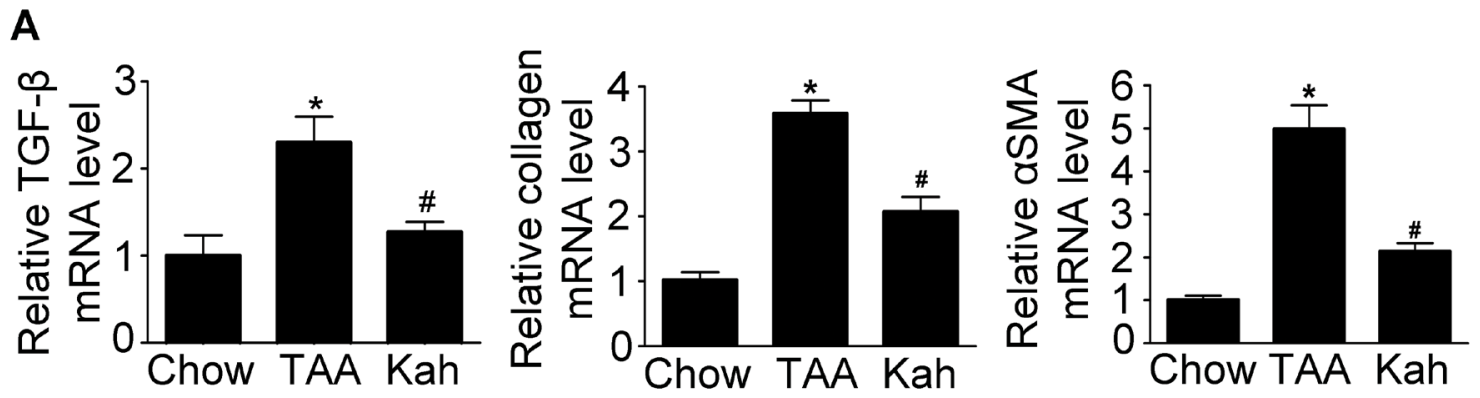

B
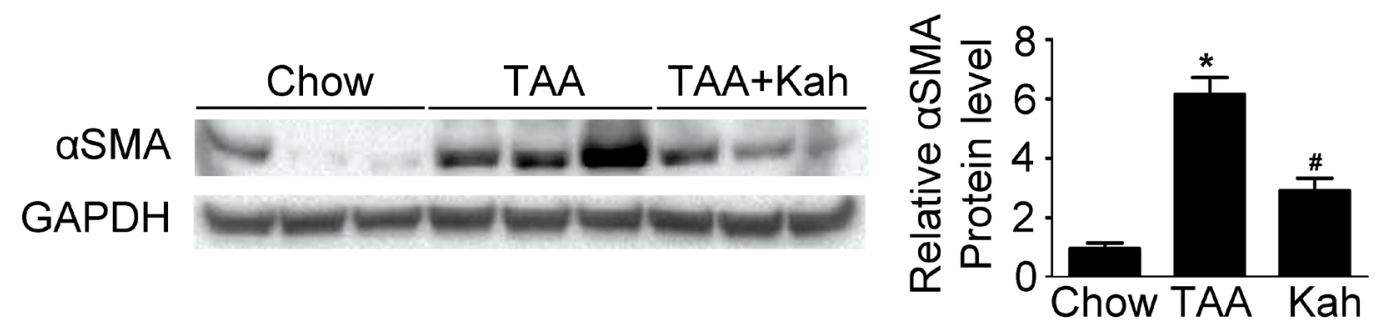

C
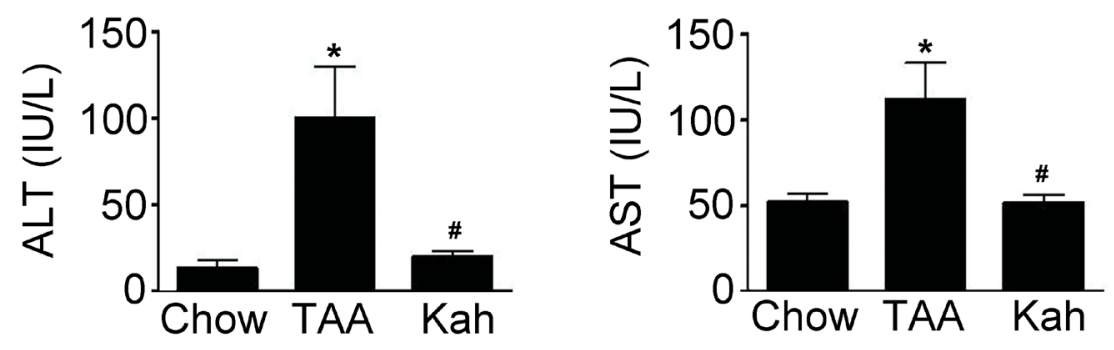

Figure 2: Kahweol decreases collagen and $\alpha$-SMA expression and serum transaminase levels in liver. (A) Representative real-time RT-PCR analysis of type I collagen and $\alpha$-SMA mRNA expression in the liver. Data in the bar graph are mean \pm SEM of three independent measurements. ${ }^{*} P<0.05$ compared with chow group, ${ }^{\#} P<0.05$ compared with TAA-injection group. (B) Representative western blot analysis of $\alpha$-SMA protein expression in the liver. Data represented in the bar graph are the mean $\pm \mathrm{SEM}$ of three independent measurements. ${ }^{*} P<0.05$ compared with chow group, ${ }^{\sharp} P<0.05$ compared with TAA-injection group. (C) Effect of kahweol on serum ALT and AST levels in TAA-treated mice. Serum ALT and AST levels were determined in serum sample by colorimetric assays. Data in the bar graph are mean \pm SEM of three independent measurements. ${ }^{*} P<0.05$ compared with chow group, ${ }^{\sharp} P<0.05$ compared with TAA-injection group. 
A
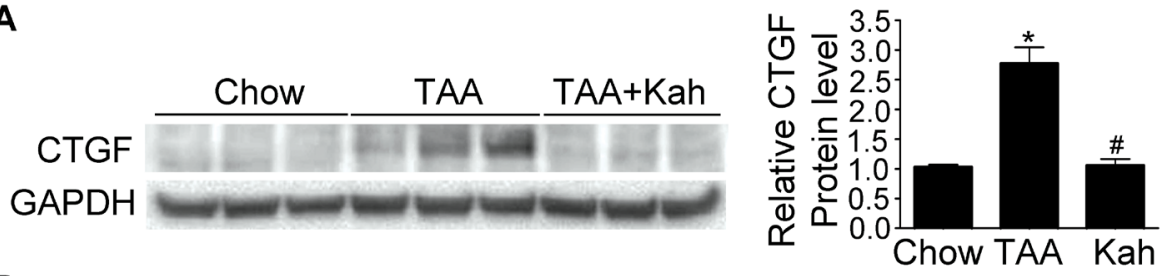

B

AML12
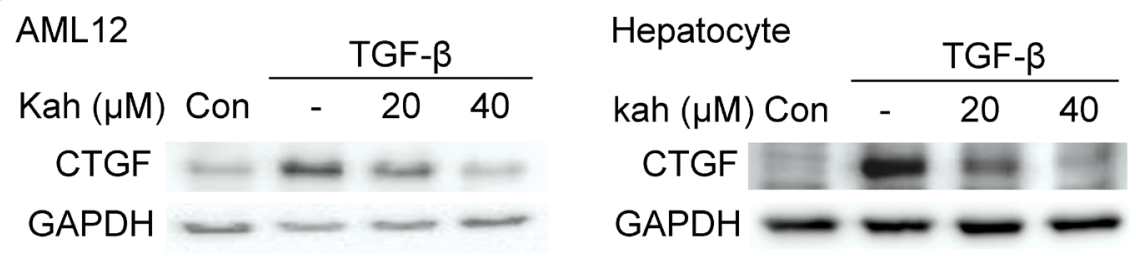

C

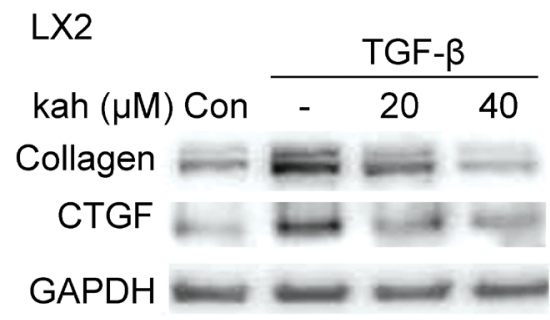

Figure 3: Effect of kahweol on CTGF expression. (A) Representative western blot analysis of CTGF protein expression in the liver. Data in the bar graph are mean \pm SEM of three independent measurements. ${ }^{*} P<0.05$ compared with chow group, ${ }^{*} P<0.05$ compared with TAA-injection group. (B) Western blot analysis showing the effect of kahweol on TGF- $\beta$-induced CTGF protein expression. AML12 cells and primary hepatocytes were incubated with various concentrations of kahweol with TGF- $\beta$ for $24 \mathrm{~h}$. (C) Western blot analysis showing the effect of kahweol on TGF- $\beta$-induced CTGF protein expression in LX2 cells.

A

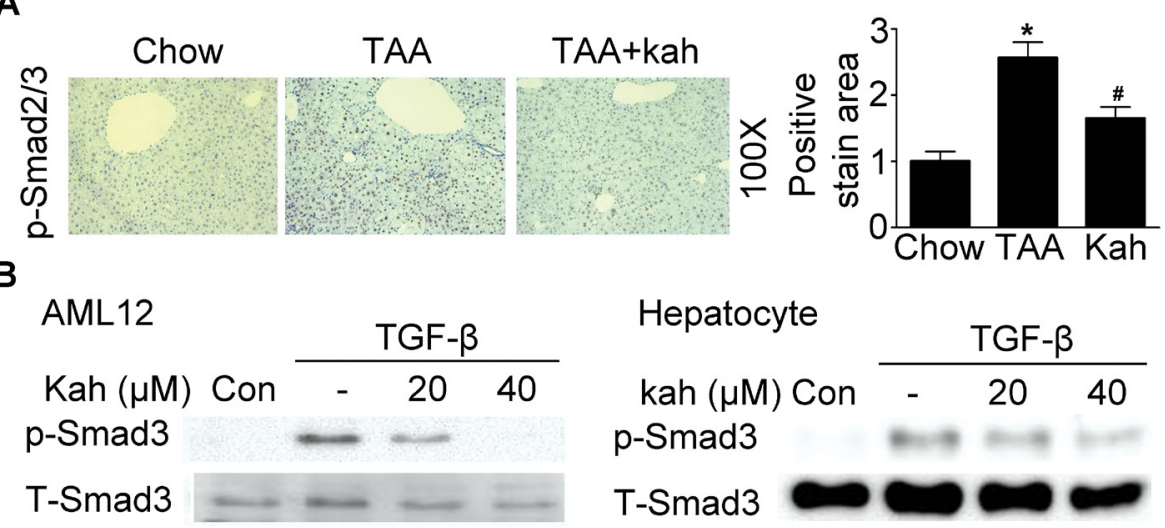

C

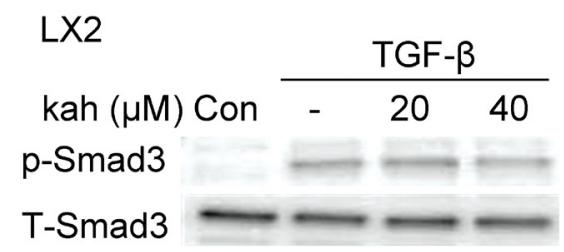

Figure 4: Effect of kahweol on Smad3 phosphorylation. (A) Representative images of phospho-Smad2/3 staining of liver tissue sections from mice after TAA-injection. Areas of positive staining with phospho-Smad2/3 were quantitated by computer-based morphometric analysis. Data are mean \pm SEM of five random fields from each liver. Magnification: $100 \mathrm{X} .{ }^{*} P<0.05$ compared with chow group, ${ }^{*} P<0.05$ compared with TAA-injection group. (B) Western blot analysis showing the effect of kahweol on TGF- $\beta$-induced phosphoSmad3 expression. AML12 cells and primary hepatocytes were incubated with various concentrations of kahweol with TGF- $\beta$ for $1 \mathrm{~h}$. (C) Western blot analysis showing the effect of kahweol on TGF- $\beta$-induced phospho-Smad3 expression in LX2 cells. 
and kahweol decreased phospho-STAT3 expression (Figure 5A). Consistent with the results of the in vivo study, kahweol treatment decreased TGF- $\beta$-stimulated phospho-STAT3 expression in AML12 cells and primary hepatocytes, but not in LX2 cells (Figure 5B and 5C).

\section{Kahweol inhibited phospho-ERK and JNK expression}

We next examined the effect of kahweol on MAP kinase pathways. Phospho-ERK and JNK expressions were increased in the livers of the TAA-treated group, but decreased in the kahweol-treated group (Figure $6 \mathrm{~A})$. Kahweol significantly decreased TGF- $\beta$-stimulated phospho-ERK and JNK expression in primary hepatocytes only (Figure 6B and 6C).

\section{DISCUSSION}

The results of this study show that kahweol decreased hepatic fibrosis induced by TAA and inhibited TGF- $\beta$-stimulated CTGF expression. The inhibitory effect of kahweol on hepatic fibrosis was associated with downregulation of TGF- $\beta$-stimulated phospho-Smad3, STAT3, ERK, and JNK expression.

Coffee consumption is associated with reduced risk and severity of liver disease. Coffee inhibited the progression of liver fibrosis by inhibiting HSC activation and reducing the expression of TGF- $\beta$ [16, 17, 20-22]. These effects have also been demonstrated in several large-scale human cohort studies. These protective effects of coffee are known to be due to caffeine among the various constituents of coffee. In a study of chronic hepatitis $\mathrm{C}$ patients who underwent liver biopsy, consumption of caffeine was associated with lowered risk of liver fibrosis [23]. However, this protective effect was afforded only by caffeine derived from coffee and not that present in the other beverages, including pure caffeine. Therefore, it is expected that coffee contains other constituents besides caffeine that have hepatoprotective effect. Among the various constituents of coffee, kahweol has been considered unhealthy because it was reported to raise the levels of total cholesterol and LDL in a study on a small number of people. However, recent studies have shown that kahweol has various beneficial effects such as

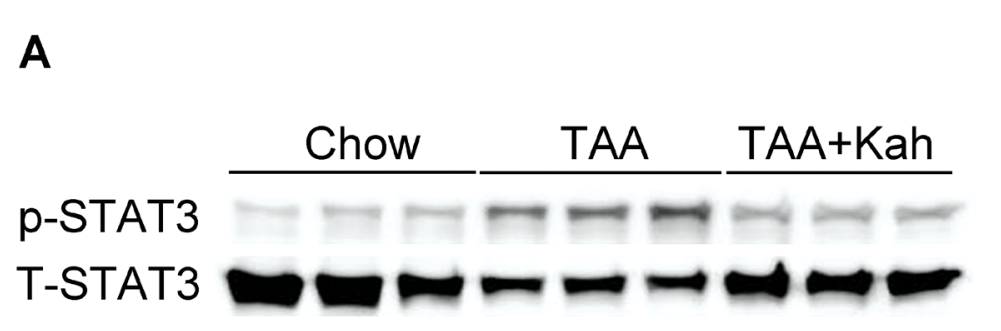

B
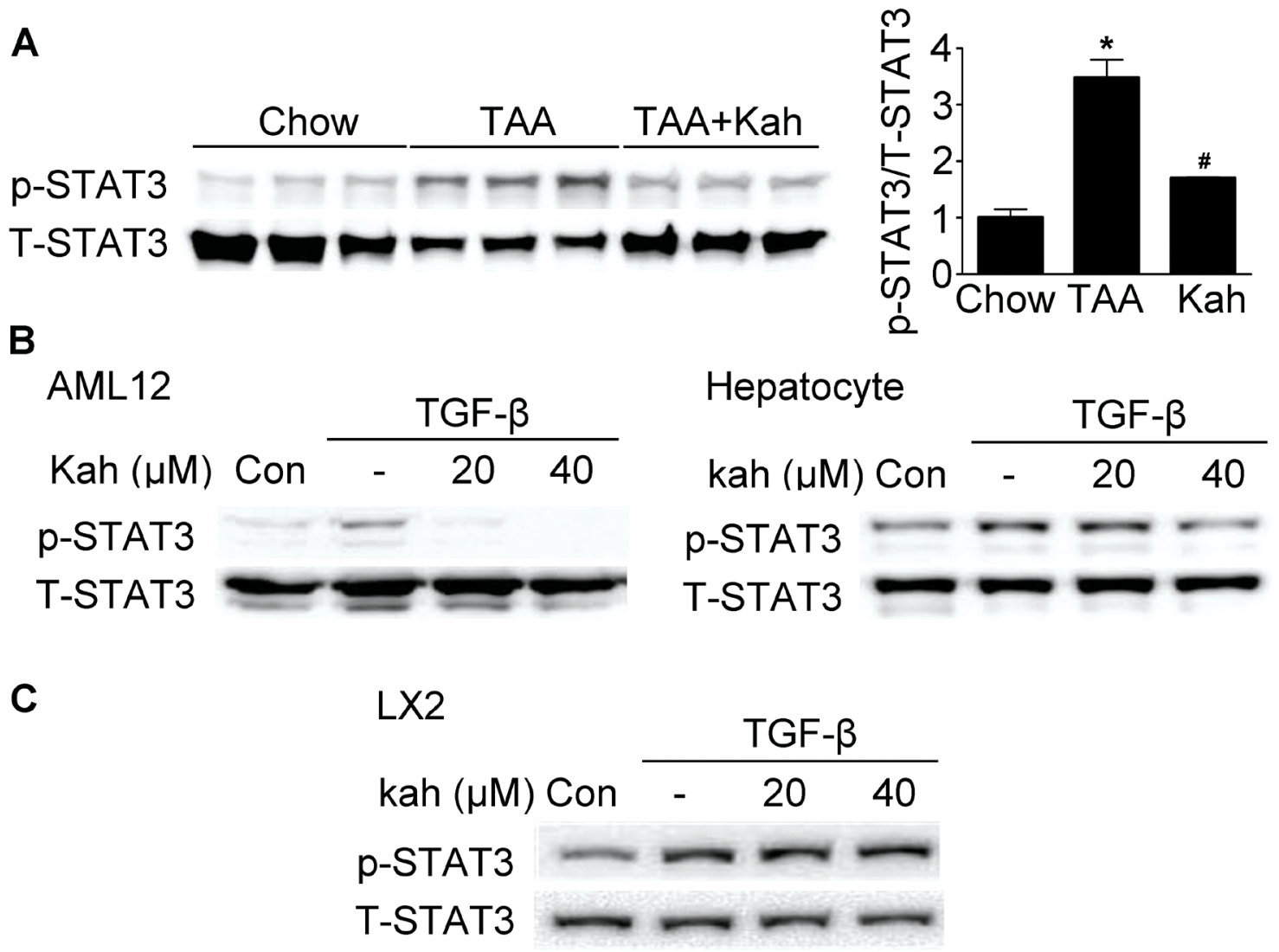

Figure 5: Effect of kahweol on STAT3 phosphorylation. (A) Representative western blot analysis of phospho-STAT3 expression in the liver. Data in the bar graph are the mean \pm SEM of three independent measurements. ${ }^{*} P<0.05$ compared with chow group, ${ }^{\#} P<$ 0.05 compared with TAA-injection group. (B) Western blot analysis showing the effect of kahweol on TGF- $\beta$-induced phospho-STAT3 expression. AML12 cells and primary hepatocytes were incubated with various concentrations of kahweol with TGF- $\beta$. (C) Western blot analysis showing the effect of kahweol on TGF- $\beta$-induced phospho-STAT3 expression in LX2 cells. 
anti-cancerous, anti-angiogenic, and anti-inflammatory effects [7, 24-26]. In another study, kahweol decreased hepatotoxicity by decreasing cytochrome P450 2E1 activity in an animal model [27]. In this study, kahweol significantly decreased TAA-induced ECM accumulation in vivo and TGF- $\beta$-stimulated collagen expression in vitro.

CTGF is strongly expressed in fibrotic liver and acts downstream of TGF- $\beta$ to modulate extracellular matrix production. Earlier studies have shown that coffee decreases CTGF expression and prevents hepatic fibrosis $[16,17]$. However, it is unclear what constituents of the coffee have this effect. In this study, kahweol significantly decreased TAA-induced CTGF expression in the liver and TGF- $\beta$-stimulated CTGF expression in hepatocytes and HSCs.

Other studies reported that induction of CTGF by TGF- $\beta$ is mediated via activation of STAT3 and Smad3 $[28,29]$. Therefore, we investigated whether the protective effect of kahweol is mediated through the inhibition of TGF- $\beta / \mathrm{Smad} 3$ or TGF- $\beta$ /STAT3 signaling. In this study, kahweol significantly decreased phospho-Smad3 and STAT3 expressions in the TAA-treated group. Kahweol decreased TGF- $\beta$-stimulated phospho-Smad3 and STAT3 expressions in hepatocytes, but not in HSCs. Our results show that hepatocytes also employ the same signaling activity in TGF- $\beta$-mediated CTGF expression as HSCs. However, kahweol inhibits this signaling pathway in hepatocytes, but not in HSCs.

CTGF has also been reported to be activated by other signaling molecules such as ERK, JNK, and p38 $[30,31]$. In our study, kahweol decreased phospho-ERK and JNK expressions in TAA-induced fibrotic livers and cultured hepatocytes. However, unlike that in hepatocytes, phospho-JNK and ERK expressions did not change after kahweol treatment in LX2 cells. These results suggest that the antifibrotic effect of kahweol in HSCs does not involve these signaling pathways. Therefore, additional studies are needed to elucidate the mechanism of the anti-fibrotic effect of kahweol on HSCs.

In conclusion, we found that kahweol significantly decreased TAA-induced hepatic fibrosis and inhibited TGF- $\beta$-stimulated CTGF expression. These results suggest that kahweol may be a new candidate agent for treating liver fibrosis.
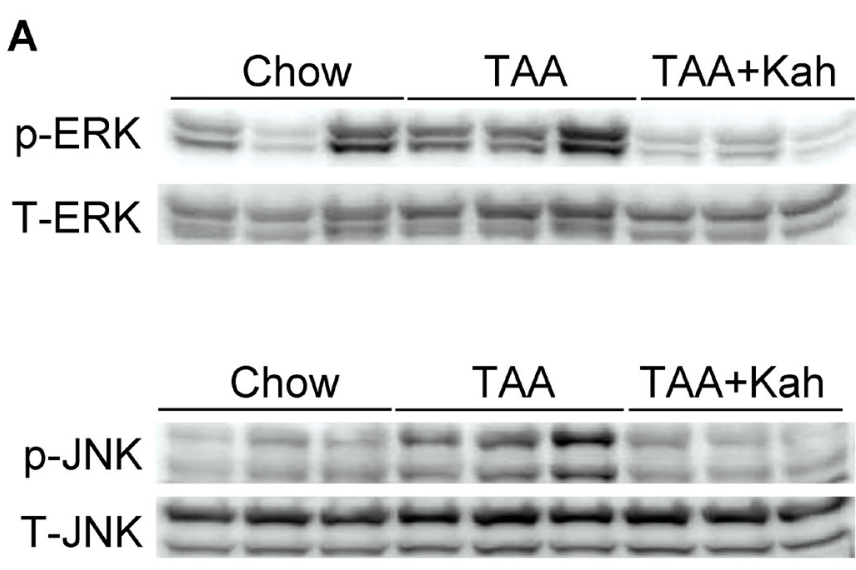

B

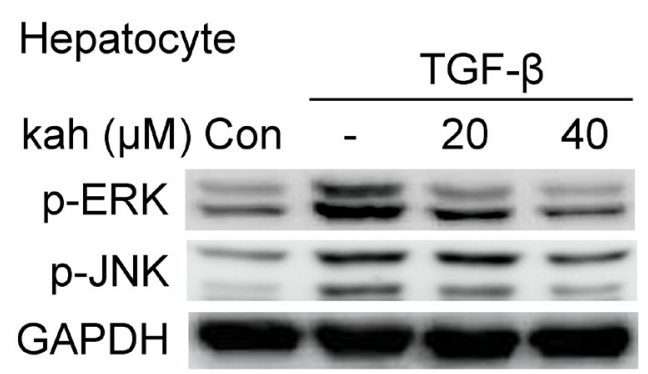

C

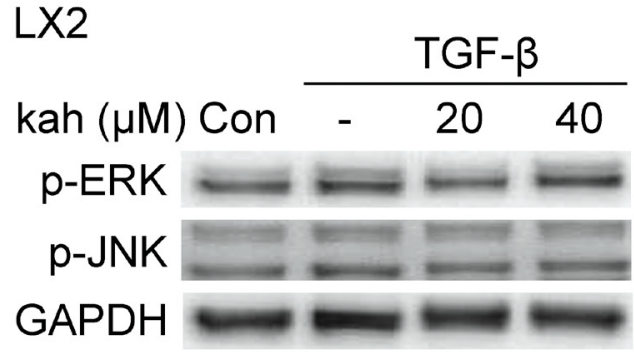

Figure 6: Effect of kahweol on the expression of phospho-ERK and phospho-JNK. (A) Representative western blot analysis of phospho-ERK and phospho-JNK expression in the liver. Data in the bar graph are mean \pm SEM of three independent measurements. ${ }^{*} P<$ 0.05 compared with chow group, ${ }^{\#} P<0.05$ compared with TAA-injection group. (B) Western blot analysis showing the effect of kahweol on TGF- $\beta$-induced phospho-ERK and phospho-JNK expression. Primary hepatocytes were incubated with various concentrations of kahweol with TGF- $\beta$. (C) Western blot analysis showing the effect of kahweol on TGF- $\beta$-induced phospho-ERK and phospho-JNK expression in LX2 cells 


\section{MATERIALS AND METHODS}

\section{Materials}

Kahweol was purchased from LKT Laboratories Inc (St Paul, MN, USA). A 40 mM solution of kahweol was initially prepared in DMSO, stored as small aliquots at $-20^{\circ} \mathrm{C}$, and thawed and diluted in cell culture medium, as required. Thioacetamide (TAA) was purchased from Sigma Aldrich (St. Louis, MO, USA) and recombinant human TGF- $\beta$, (5 ng/mL) was purchased from R\&D Systems (Minneapolis, MN, USA). The anti-CTGF antibody and anti-phospho-Smad2/3 antibodies were purchased from Santa Cruz (Dallas, TX, USA). Anti-Collagen antibody was purchased from Abcam (Cambridge, UK) and antiaSMA antibody was purchased from Sigma Aldrich. AntiGAPDH antibody, anti-phospho-Smad3 (Ser423/425) antibody, anti-phospho-ERK (Th202/Tyr204) antibody, anti-phospho-JNK (Thr182/Tyr185) antibody and antiphospho-STAT3 (Tyr705) were purchased from Cell Signaling Technology (Beverly, MA, USA).

\section{Animal study}

Male 8-week-old C57BL/6 mice were purchased from Hanasangsa (Pusan, Korea) and housed in a facility equipped with $12 \mathrm{~h}$ light/dark cycle. All procedures were performed in accordance with the institutional guidelines for animal research (KM-2013-51R1). Kahweol was administered orally premixed with the milled pellet (FEEDLAB, Guri, Korea). Mice were divided into three groups and were fed either a chow diet (control, $n=5$ ), a chow diet with TAA injection (TAA $200 \mathrm{mg} / \mathrm{kg}$ of body weight, $n=7)$, or a chow diet supplemented with kahweol $(75 \mathrm{mg} / \mathrm{kg})$ and TAA injection (TAA+Kah, $\mathrm{n}=7)$. Liver fibrosis was induced by intraperitoneal injection of TAA dissolved in saline, thrice a week for 8 weeks. Kahweol was administered orally, premixed with the milled pellet (FEEDLAB, Guri, Korea). We measured body weight and food intake of mice three times a week. After 8 weeks, animals were euthanized forthe collection of blood and liver tissue samples.

\section{Cell culture}

Mouse hepatocyte AML-12 cell line was purchased form the American Type Culture Collection (Manassas, VA). AML12 cells were cultured in 5\% $\mathrm{CO}_{2} / 95 \%$ air at $37^{\circ} \mathrm{C}$ in DMEM/F12 medium (GIBCO-BRL, Grand island, NY) supplemented with $10 \%$ fetal bovine serum (Hyclone, Logan, UT), insulin-transferrin-selenium (ITS; GIBCO-BRL), dexamethaosone (40 ng/mL; Sigma) and antibiotics (Anti-Anti: GIBCO-BRL). LX2, human hepatic stellate cell line, was a kind gift from Dr. Jeong (Korea Advanced Institute of Science and Technology, Daejeon, Korea). The LX2 cells were cultured in 5\% $\mathrm{CO}_{2} / 95 \%$ air at $37^{\circ} \mathrm{C}$ in DMEM (GIBCO-BRL) supplemented with $10 \%$ fetal bovine serum and antibiotics. Cells were treated with chemicals in $0.5 \%$ FBS with or without TGF- $\beta(5 \mathrm{ng} / \mathrm{ml})$, and then subsequently processed for isolation of protein and RNA as described below.

\section{Primary cultures of hepatocytes}

C57BL/6 hepatocytes were isolated by perfusing the liver via the portal vein. The liver was perfused with resuspension buffer $(5.4 \mathrm{mmol} / \mathrm{L} \mathrm{KCl}, 0.44 \mathrm{mmol} / \mathrm{L}$ $\mathrm{KH}_{2} \mathrm{PO}_{4}, 140 \mathrm{mmol} / \mathrm{L} \mathrm{NaCl}, 0.34 \mathrm{mmol} / \mathrm{L} \mathrm{Na} 2 \mathrm{HPO}_{4}, 0.5$ $\mathrm{mmol} / \mathrm{L}$ EGTA, $25 \mathrm{mmol} / \mathrm{L}$ Tricine, $\mathrm{pH}$ 7.2) at $5 \mathrm{~mL} / \mathrm{min}$ for $10 \mathrm{~min}$ and then perfused with collagenase solution [collagenase type I (Worthington Biochemical Corp, Freehold, New Jersey), $0.75 \mathrm{mg} / \mathrm{ml}, \mathrm{pH} 7.2]$ at $5 \mathrm{~mL} / \mathrm{min}$ for 10 minutes. After perfusion, the liver was shaken for $20 \mathrm{~min}$ at $37^{\circ} \mathrm{C}$ and filtered through a mesh $(85 \mu \mathrm{m}$ nylon mesh). Hepatocytes were collected by centrifugation at $42 \times g$ for 5 minutes at $4^{\circ} \mathrm{C}$, resuspended in William's $\mathrm{E}$ medium (Sigma), and seeded onto type I collagen-coated 60-mm dishes (IWAKI Scitech Kiv, Tokyo, Japan) at a density of $5 \times 10^{5}$ cells $/ \mathrm{mL}$. The viability of hepatocytes, as measured by trypan blue dye exclusion, was always greater than $85 \%$. After a 2- to 3-hour incubation, the medium was exchanged with DMEM. Hepatocytes were treated with chemicals in $0.5 \%$ FBS with or without TGF- $\beta$ ( $5 \mathrm{ng} / \mathrm{ml}$ ), and then subsequently processed for isolation of protein and RNA as described below.

\section{Histological and immunohistohistochemical analysis}

Liver tissue was fixed in 4\% formaldehyde solution and embedded in paraffin, and $4-\mu \mathrm{m}$ section were cut. Liver sections were deparaffinized in xylene and rehydrated through graded ethanol concentration.

Histochemical staining was performed with H\&E and Sirius Red. For Sirius red staining. Immunohistochemical staining was performed using anti-Collagen, anti- $\alpha$ SMA, anti-phospho-Smad2/3 and anti-CTGF primary antibodies followed by horseradish peroxidase conjugated anti-mouse, anti-rabbit, or anti-goat IgG secondary antibodies (Dako, Glostrup, Denmark), according to the manufacturer's instructions. All data were normalized to the chow diet $(=1)$ and in all bar graphs were expressed as fold increase relative to the chow diet.

\section{Quantitative real-time (qRT)-RCR}

Total RNA was isolated from cells and tissue extracts, using the Trizol reagent (Invitrogen, MA, USA). Reverse transcription was performed using the Maxima First Strand cDNA synthesis kit (Thermo scientific, MA, USA). Quantitative real-time RT-PCR was performed using a SYBR Green PCR master mix kit (Roche Diagnostics, 
Indianapolis, Indiana) and a Light Cycler 96 instrument (Roche Diagnostics). PCR parameters were as follows: 45 cycles of $95^{\circ} \mathrm{C}$ for $30 \mathrm{~s}, 60^{\circ} \mathrm{C}$ for $10 \mathrm{~s}$, and $72^{\circ} \mathrm{C}$ for $15 \mathrm{~s}$. Primer sequences were as follows: human Collagen forward, 5'-CACACGTCTCGGTCATGGTA-3', and reverse, 5'-AAGAGGAAGGCCAAGTCGAG-3'; mouse collagen forward, 5'- GCCTTGGAGGAAACTTTGCTT3' and reverse, 5'- GCACGGAAACTCCAGCTGAT -3'; human CTGF forward, 5'-CACCCGGGTTACCAATGACA-3', and reverse, 5'-TCCGGGACAGTTGTAATGGC-3'; mouse CTGF forward, 5'-CCAGACCCAACTATGATGCG-3', and reverse, 5'-GTGTCCGGATGCACTTTTTG-3'; mouse TGF- $\beta$ forward, 5'-AAATCAACGGGATCAGCCCC-3', and reverse, 5'-GGATCCACTTCCAACCCAGG-3'; mouse $\quad \alpha S M A$ forward, 5' CAGGCTGTGCTGTCCCTCTA - 3', and reverse, 5'CGGCAGTAGTCACGAAGGAA - 3'; human GAPDH forward, 5'-GGAGCCAAAAGGGTCATCAT-3', and reverse, 5'-GTGATGGCATGGACTGTGGT-3'; mouse GAPDH forward, 5'- ACGACCCCTTCATTGACCTC -3', and reverse, 5'- ATGATGACCCTTTTGGCTCC-3'. GAPDH was used as an internal standard.

\section{Western blot analysis}

Cells were harvested in lysis buffer $[50 \mathrm{mM}$ Tri-HCl (pH 8.0), $150 \mathrm{mM} \mathrm{NaCl,} 1 \mathrm{mM}$ EDTA, 1\% TritonX-100, and $0.5 \%$ Na-deoxycholate] containing protease/phosphatase inhibitors and dithiothreitol. The cells were lysed on ice for $30 \mathrm{~min}$ and lysate was collected by centrifugation at $13,000 \mathrm{rpm}$ for $10 \mathrm{~min}$. Protein quantification was performed using a BCA protein assays (Thermo scientific). Cell lysates of $10 \mu \mathrm{g}$ were separated by SDS-PAGE and then transferred electrophoretically to a polyvinylidene difluoride membrane (Millipore, Bedford, MA). The membrane was incubated serially in a blocking buffer (5\% skim milk in Tris-buffered salin contain $0.1 \%$ Tween 20), primary antibody and appropriate horseradish peroxidase-conjugated secondary antibody, and then developed using the Clarity ${ }^{\mathrm{TM}}$ Western ECL substrate kit (Bio-Rad, Richmond, CA). The membrane was reprobed with anti-GAPDH to verify equal loading of protein in each lane. Signal intensities were quantitated by densitometry using the ImageJ software (NIH, Bethesda, MD, USA).

\section{Serum biochemical assays}

The serum AST and ALT levels were measured using an auto-chemical analyzer (Hitachi 747, Tokyo, Japan) and an ultraviolet assay method.

\section{Statistical analysis}

Data are expressed as means \pm SEM. ANOVA was used to determine significant differences in multiple comparisons and was performed by the Duncan test. Values of $\mathrm{P}<0.05$ were considered statistically significant

\section{CONFLICTS OF INTEREST}

The authors disclose no conflicts of interest.

\section{FUNDING}

This work was supported by grants (HI16C1501) from the Korea Health technology R\&D Project through the Korea Health Industry Development Institute (KHIDI), funded by the Ministry of Health \& Welfare, Republic of Korea and the National Research Foundation of Korea (NRF) Grant funded by the Korea Government (MSIP) (2014R1A5A2010008 and 2015R1C1A2A01052054).

\section{REFERENCES}

1. Higdon JV, Frei B. Coffee and health: a review of recent human research. Crit Rev Food Sci Nutr. 2006; 46:101-123.

2. Morisco F, Lembo V, Mazzone G, Camera S, Caporaso N. Coffee and liver health. J Clin Gastroenterol. 2014; 48:S87-S90.

3. Butt MS, Sultan MT. Coffee and its consumption: benefits and risks. Crit Rev Food Sci Nutr. 2011; 51:363-373.

4. Nkondjock A. Coffee consumption and the risk of cancer: an overview. Cancer Lett. 2009; 277:121-125.

5. Nicoletti A, Zappia M. Coffee consumption and risk of levodopa-induced dyskinesia in Parkinson's disease: The FRAGAMP study. Mov Disord. 2015; 30:1854-1856.

6. Gross G, Jaccaud E, Huggett AC. Analysis of the content of the diterpenes cafestol and kahweol in coffee brews. Food Chem Toxicol. 1997; 35:547-554.

7. Cardenas C, Quesada AR, Medina MA. Anti-angiogenic and anti-inflammatory properties of kahweol, a coffee diterpene. PLoS One. 2011; 6:e23407.

8. Park GH, Song HM, Jeong JB. The coffee diterpene kahweol suppresses the cell proliferation by inducing cyclin D1 proteasomal degradation via ERK1/2, JNK and GKS3beta-dependent threonine-286 phosphorylation in human colorectal cancer cells. Food Chem Toxicol. 2016; 95:142-148.

9. Friedman SL. Liver fibrosis -- from bench to bedside. J Hepatol. 2003; 38:S38-S53.

10. Bataller R, Brenner DA. Liver fibrosis. J Clin Invest. 2005; 115:209-218.

11. Iredale JP. Hepatic stellate cell behavior during resolution of liver injury. Sem Liver Dis. 2001; 21:427-436.

12. Gressner OA, Gressner AM. Connective tissue growth factor: a fibrogenic master switch in fibrotic liver diseases. Liver Int. 2008; 28:1065-1079. 
13. Rachfal AW, Brigstock DR. Connective tissue growth factor (CTGF/CCN2) in hepatic fibrosis. Hepatol Res. 2003; 26:1-9.

14. Tamatani T, Kobayashi H, Tezuka K, Sakamoto S, Suzuki K, Nakanishi T, Takigawa M, Miyano T. Establishment of the enzyme-linked immunosorbent assay for connective tissue growth factor (CTGF) and its detection in the sera of biliary atresia. Biochem Biophys Res Commun. 1998; 251:748-752.

15. Zhang D, Wang NY, Yang CB, Fang GX, Liu W, Wen J, Luo C. The clinical value of serum connective tissue growth factor in the assessment of liver fibrosis. Digest Dis Sci. 2010; 55:767-774.

16. Arauz J, Moreno MG, Cortes-Reynosa P, Salazar EP, Muriel P. Coffee attenuates fibrosis by decreasing the expression of TGF-beta and CTGF in a murine model of liver damage. J Appl Toxicol. 2013; 33:970-979.

17. Arauz J, Zarco N, Segovia J, Shibayama M, Tsutsumi V, Muriel P. Caffeine prevents experimental liver fibrosis by blocking the expression of TGF-beta. Eur J Gastroenterol Hepatol. 2014; 26:164-173.

18. Wahab NA, Weston BS, Mason RM. Modulation of the TGFbeta/Smad signaling pathway in mesangial cells by CTGF/CCN2. Exp Cell Res. 2005; 307:305-314.

19. Kong X, Horiguchi N, Mori M, Gao B. Cytokines and STATs in Liver Fibrosis. Front Physiol. 2012; 3:69.

20. Vitaglione P, Morisco F, Mazzone G, Amoruso DC, Ribecco MT, Romano A, Fogliano V, Caporaso N, D'Argenio G. Coffee reduces liver damage in a rat model of steatohepatitis: the underlying mechanisms and the role of polyphenols and melanoidins. Hepatology. 2010; 52:1652-1661.

21. Moreno MG, Chavez E, Aldaba-Muruato LR, Segovia J, Vergara P, Tsutsumi V, Shibayama M, Rivera-Espinoza Y, Muriel P. Coffee prevents CCl(4)-induced liver cirrhosis in the rat. Hepatol Int. 2011; 5:857-863.

22. Chen S, Teoh NC, Chitturi S, Farrell GC. Coffee and non-alcoholic fatty liver disease: brewing evidence for hepatoprotection? J Gastroenterol Hepatol. 2014; 29:435-441.
23. Modi AA, Feld JJ, Park Y, Kleiner DE, Everhart JE, Liang TJ, Hoofnagle JH. Increased caffeine consumption is associated with reduced hepatic fibrosis. Hepatology. 2010; 51:201-209.

24. Kim HG, Hwang YP, Jeong HG. Kahweol blocks STAT3 phosphorylation and induces apoptosis in human lung adenocarcinoma A549 cells. Toxicol Lett. 2009; 187:28-34.

25. Oh JH, Lee JT, Yang ES, Chang JS, Lee DS, Kim SH, Choi YH, Park JW, Kwon TK. The coffee diterpene kahweol induces apoptosis in human leukemia U937 cells through down-regulation of Akt phosphorylation and activation of JNK. Apoptosis. 2009; 14:1378-1386.

26. Moeenfard M, Cortez A, Machado V, Costa R, Luis C, Coelho P, Soares R, Alves A, Borges N, Santos A. Antiangiogenic properties of cafestol and kahweol palmitate diterpene esters. J Cell Biochem. 2016; 117:2748-2756.

27. Lee KJ, Choi JH, Jeong HG. Hepatoprotective and antioxidant effects of the coffee diterpenes kahweol and cafestol on carbon tetrachloride-induced liver damage in mice. Food Chem Toxicol. 2007; 45:2118-2125.

28. Liu Y, Liu H, Meyer C, Li J, Nadalin S, Konigsrainer A, Weng H, Dooley S, ten Dijke P. Transforming growth factor-beta (TGF-beta)-mediated connective tissue growth factor (CTGF) expression in hepatic stellate cells requires Stat3 signaling activation. J Biol Chem. 2013; 288:30708-30719.

29. Parada C, Li J, Iwata J, Suzuki A, Chai Y. CTGF mediates Smad-dependent transforming growth factor beta signaling to regulate mesenchymal cell proliferation during palate development. Mol Cell Biol. 2013; 33:3482-3493.

30. Arnott JA, Zhang X, Sanjay A, Owen TA, Smock SL, Rehman S, DeLong WG, Safadi FF, Popoff SN. Molecular requirements for induction of CTGF expression by TGFbeta1 in primary osteoblasts. Bone. 2008; 42:871-885.

31. Tan TW, Lai CH, Huang CY, Yang WH, Chen HT, Hsu HC, Fong YC, Tang CH. CTGF enhances migration and MMP13 up-regulation via alphavbeta3 integrin, FAK, ERK, and NF-kappaB-dependent pathway in human chondrosarcoma cells. J Cell Biochem. 2009; 107:345-356. 